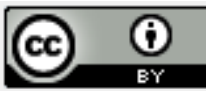

\title{
AVALIAÇÃO DA INADIMPLÊNCIA EM INSTITUIÇÕES DE ENSINO PRIVADAS: APLICAÇÃO DA RESOLUÇÃO 2682/99 DO BANCO CENTRAL DO BRASIL
}

\author{
PROBABILTY OF DEFAULT EVALUATION IN PRIVATE HIGH \\ SCHOOLS: BRAZILIAN CENTRAL BANK 2682/99 RESOLUTION \\ APPLICATION
}

\section{Edson Erthal de Medeiros}

Mestrando

Pontifícia Universidade Católica do Paraná

Programa de Pós-Graduação em Administração

Rua Imaculada Conceição, 1155 - Curitiba PR - 88.215-901

(41)3271-1476 edson.medeiros@usb.org.br

\section{Wesley Vieira da Silva}

Professor

Pontifícia Universidade Católica do Paraná

Programa de Pós-Graduação em Administração

Rua Imaculada Conceição, 1155 - Curitiba PR - 88.215-901

(41)3271-1260 wesley.vieira@pucpr.br

\section{Luiz Carlos Duclós \\ Professor}

Pontifícia Universidade Católica do Paraná

Programa de Pós-Graduação em Administração

Rua Imaculada Conceição, 1155 - Curitiba PR - 88.215-901

(41)3271-1257 luiz.duclos@ pucpr.br 


\title{
RESUMO
}

O objetivo deste trabalho é aplicar a Resolução 2682/99 do BB para a identificação das matrículas inadimplentes por faixa de atraso e cálculo de uma possível Provisão Para Devedores Duvidosos. O estudo se caracteriza como uma pesquisa qualitativa descritiva. Foram analisadas 21 IPEFMs no Estado do Paraná / Brasil, pertencentes a uma mantenedora, utilizando os critérios constantes na referida resolução para os anos de 2004, 2005 e 2006. A comparação ano a ano dos resultados obtidos com os valores calculados pelo critério de Perdas Líquidas e Perdas Potenciais, conclui que somente a aplicação da resolução 2682/99 não é totalmente compatível com as características dos créditos de uma IPEFM ou mantenedora. Há indícios de que a probabilidade de perda potencial calculada para o ano de 2004 foi de $2,45 \%$, no ano de 2005 de $2,01 \%$ e no ano de 2006 de $1,17 \%$, confirmando sua redução ao longo do tempo.

Palavras-chave: Resolução 2682/99, Inadimplência, Instituições de Ensino

\begin{abstract}
This study aims the application of Brazilian Central Bank 2682/99 Resolution to identify the Probability of Default ranked by time and the Probability of Default provision. This study is characterized as a descriptive/qualitative research. The sample of twenty-one Private High Schools of the Paraná State/Brazil, of one holding, was analyzed using the criteria of Brazilian Central Bank 2682/99 Resolution during the years of 2004, 2005 and 2006. The comparison of results year by year, using Net Profitability of Default and Potential Loss criteria, concluded that the 2682/99 Resolution application is not totally compatible with the credit characteristics of the Brazilian educational institutions. There are evidence that the Potential Loss calculated for the 2004, 2005 and 2006 years was $2.4 \%, 2.01 \%$ and $1.17 \%$ respectively showing a reduction over time.
\end{abstract}

Key-words: Resolution 2682/99, Probability of Default, Private High Schools

\section{INTRODUÇÃO}

O risco, como bem posto por Bernstein (1998), faz parte do dia a dia das pessoas. É tão natural que muitos não notam o quanto as decisões tomadas podem afetar o futuro. O risco está presente no fato de se atravessar uma rua fora da faixa de segurança, no ato de dirigir um carro, de se usar ou não cinto de segurança, de se usar o corrimão ou não ao se descer uma escada, de ligar um fogão, nos jogos de azar e, para efeito deste estudo, nas grandes corporações a exemplo das decisões de investimentos e nos créditos concedidos.

Toda a decisão que diz respeito à produção de um bem ou serviço possui um componente relativo de risco a ela associado. Ao decidir aplicar os seus recursos financeiros 


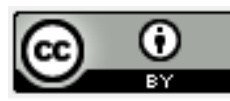

em uma determinada organização, os acionistas, proprietários ou organização esperam auferir um determinado retorno em função desses investimentos, que normalmente é proporcional aos riscos que foram incorridos na decisão.

As mudanças testemunhadas na economia brasileira após a introdução do Plano Real em julho de 1994, alçaram a questão de administração de risco de crédito e inadimplência, a uma posição de destaque nas instituições financeiras locais. Antes disso, a alta inflação havia inibido o crescimento do mercado de empréstimos no país.

Prado, Bastos e Duarte Jr. (2000), mostram que ao invés de emprestar à clientes do setor privado, a um risco de crédito maior, os grandes bancos comerciais preferiam financiar a dívida interna do país, a um risco de crédito menor, com maior liquidez, mas ainda assim cobrando taxas de juros substanciais.

A expansão das operações de crédito, no Brasil após o Plano Real foi abrangente em vários segmentos da economia, entretanto, as operações de crédito para pessoas físicas foram as que mais cresceram nos últimos anos. As informações consolidadas divulgadas pelo Banco Central do Brasil para cada modalidade de crédito do sistema financeiro nacional mostram que já no início do ano 2001 o saldo total das operações concedidas a pessoas físicas representava um volume superior a $50 \%$ do saldo total das operações concedidas a pessoas jurídicas.

Marshall (2002, p.39), mostra que a avaliação e o gerenciamento adequado dos riscos permitem à organização uma maior utilização de financiamentos por meio de dívidas. Ele ainda menciona que o endividamento acaba criando mecanismos de economia fiscal relativos a juros, isto é, os pagamentos de juros sobre o endividamento são deduzidos ao se mensurar o lucro tributável. Em contrapartida, tais organizações não podem deduzir dividendos de seu lucro, porque aumentam a sua possibilidade de vir a passar dificuldades financeiras justificando, deste modo, a gerência de possíveis perdas catastróficas.

Securato (2002, p.181), evidencia que com todo o esforço realizado e, por mais positivo que seja a avaliação em relação ao crédito a ser concedido, só é possível conhecer o resultado da operação no seu vencimento, quando ocorre o recebimento ou não do valor pactuado pela operação de crédito. Esta falta de certeza quanto ao resultado do processo é que cria condição de risco na operação creditícia.

Atualmente, o crédito passou a ganhar espaço por parte dos sistemas financeiros, não somente em função da escassez de recursos, mas também como um risco que necessita ser controlado em situações da grande volatilidade existente no mercado. 
Sanvicente e Minardi (1999) mencionam que quando há concessão de um crédito, uma preocupação relevante está associada com a possibilidade de que o cliente venha a ter sua capacidade de pagamento comprometida, não honrando assim os compromissos que foram assumidos.

Nas IPEFMs - Instituições Privadas de Ensino Fundamental e Médio, desde 1994 até os dias de hoje, percebe-se a existência de inúmeras dificuldades financeiras, levando-os a uma situação de natureza paradoxal ano a ano, em função da elevação do número de novos estabelecimentos e, consequientemente, na oferta de vagas, contrapondo-se a uma realidade apontada pelas pesquisas do IBGE onde década após década existe um decréscimo nas taxas de natalidade trazendo como conseqüência menos discentes disponíveis. Em adição a isso, ainda ressaltam-se os investimentos substanciais realizados pelos governos estatuais e municipais melhorando a qualidade dos estabelecimentos públicos, fazendo com que haja uma migração de alunos de instituições particulares para complexos educacionais do sistema público de ensino.

As mantenedoras das IPEFMs também vêm se preocupando com o elevado crescimento da demanda de alunos da classe "C" da população brasileira. Porém, o poder aquisitivo dessa classe social não permite que as mensalidades sejam ajustadas às necessidades organizacionais.

Percebe-se, ainda, que a classe média brasileira, principal fonte de clientes das IPEFMs, teve uma queda na renda de aproximadamente $46 \%$ nos últimos 6 anos, conforme aponta matéria da Folha-online do dia 10 de dezembro de 2006. Este fato tem pressionando as mensalidades para baixo, na maioria das vezes. À medida que a renda dos clientes e potenciais clientes das IPEFMs diminuem, as receitas das mantenedoras das IPEFMs também diminuem, contribuindo assim com os índices de inadimplência e com a redução de financiamentos públicos e privados.

Com o objetivo de alcançar a compreensão do fenômeno a ser estudada tal pesquisa encontra-se orientada a responder ao seguinte questionamento: qual o impacto das características sócio-econômicas dos responsáveis financeiros dos discentes regularmente matriculados sobre os níveis de inadimplência vivenciados na organização pesquisada?

O tema proposto insere-se no contexto das decisões financeiras, tendo como foco de análise uma mantenedora de vinte e uma IPEFMs - Instituição Privada de Ensino Fundamental e Médio. Do ponto de vista estratégico, o gerenciamento adequado do crédito, fornece dados e informações importantes às instituições na forma de um conhecimento maior 


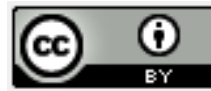

e mais amplo do perfil de usuários deste crédito, favorecendo a melhoria de sua gestão e a redução das perdas causadas pela inadimplência. Segundo Chu e Schechtman (2003) o custo da informação é um importante componente das taxas de juros e/ou serviços praticados pelas instituições, devido ao alto custo financeiro associado à coleta e manutenção de dados.

A concessão de crédito por parte de uma IPEFM a um discente e/ou seu responsável financeiro, pode ter uma conotação de um empréstimo ou mesmo de um financiamento, onde os custos são desembolsados pela prestadora dos serviços, neste caso, a mantenedora da IPEFM.

Numa IPEFM a compra de ativos fixos e/ou intangíveis, aliado a manutenção da estrutura administrativa, forma uma estrutura de gastos a ser financiada pelo próprio negócio. Ao prestar um serviço ao discente, ela espera receber os pagamentos em dia, de forma que possa honrar também com os compromissos assumidos com os fornecedores. A não constatação desse fato, certamente afeta a sua estrutura de custos, que precisa ser arcado pela mantenedora de uma IPEFM para posteriormente ser renegociado com o discente/responsável financeiro.

Verifica-se, então, que o não pagamento das mensalidades obriga a mantenedora de uma IPEFM a recorrer a fonte alternativa de financiamento, transferindo a dívida do discente para uma instituição financeira ou algo similar. Destaca-se, ainda, que independentemente dos problemas gerados pelos discentes em decorrência do não pagamento, seus direitos às aulas e a toda a estrutura de uma IPEFM são garantidos até a renovação da matrícula.

Nesse contexto, vê-se, portanto, a necessidade de uma maior preocupação por parte dos gestores dos setores econômico e financeiro das mantenedoras de IPEFMs acerca da gestão de riscos nas transações efetuadas com os discentes justificando, com isso, a escolha desse tema. Com base no exposto, o presente trabalho tem como objetivo aplicar os critérios de provisão de inadimplência constantes na resolução 2.682/99 para os dados em análise, visando identificar o montante em reais $(\mathrm{R} \$)$ da provisão para devedores duvidosos calculada. Um outro objetivo do presente trabalho é a comparação dos resultados obtidos com a aplicação da resolução 2682/99 com os resultados obtidos a partir do cálculo da Perda Líquida e da Perda potencial para os dados em análise.

Este trabalho encontra-se estruturado em cinco seções, que pode ser resumidas como: a primeira refere-se a parte introdutória; a segunda traz uma breve revisão de literatura sobre o tema abordado; a terceira enfoca os aspectos metodológicos; a quarta mostra a apresentação e 


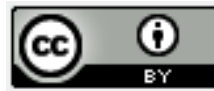

análise dos resultados empíricos e a quinta seção enfatiza as considerações finais e recomendações.

\section{REFERENCIAL TEÓRICO-EMPÍRICO}

Nesta seção procura-se dar ao leitor uma visão dos principais aspectos concernentes ao risco de crédito que dá suporte ao trabalho, sendo estruturado em duas subseções que podem ser resumidas como: a subseção 2.1 trata da análise de crédito e a subseção 2.2 trata de um resumo da resolução 2682/99 do Banco Central do Brasil.

\subsection{ANÁLISE DE CRÉDITO}

A análise de crédito é um processo que envolve a junção de todas as informações disponíveis a respeito de um determinado tomador de crédito, podendo ser pessoa física ou jurídica, com o objetivo de decidir sobre a concessão ou não de crédito.

Silva (2006) apresenta diversas ferramentas possuidoras de um suporte estatístico significativo que são usadas na avaliação do risco de crédito, a saber: os sistemas especialistas, credit scoring, behaviour scoring, rating, redes neurais, algoritmos genéticos, dentre outras.

A análise de crédito envolve as habilidades de se tomar uma decisão dentro de incertezas, de ser constantemente mutável, trabalhar com informações incompletas e em situações complexas, de forma a chegar a uma conclusão clara e factível de ser implantada.

Aliado à concessão do crédito, o envolvimento tanto dos riscos como das incertezas, são conceitos que se encontram intrinsecamente atrelados à área de estatística. Nas visões de Vaughan (1997, p.78-79), Bessis (1998, p.23-28), Zamora (1990) e Emery e Finnerty (1997, p.184-185), as abordagens comumente reportadas sobre o significado do que venha ser o risco podem ser sumarizadas como: (a) chance ou possibilidade de perdas; (b) dispersão ou probabilidade de perdas em relação aos resultados esperados; (c) incertezas.

Constata-se que a indeterminação e as perdas encontram-se presentes na maioria das definições, ficando implícita a noção de resultados indeterminados. Logo, quando o risco encontra-se presente, deve haver ao menos dois possíveis resultados: a certeza, cuja probabilidade é igual a zero ou a incerteza, cuja probabilidade é igual à unidade. 


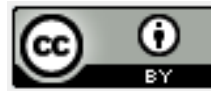

Já os autores Emery e Finnerty (1997), Gitman (1997), Ross et al (1995) e Tosta de Sá (1999) definem o risco como a mensuração da variabilidade e a mensuração da possibilidade de um resultado negativo. No que diz respeito à avaliação do risco de crédito, esta traz consigo a grande dificuldade, que é a de poder prever, antecipadamente, se um determinado cliente, a quem está sendo concedido o crédito - ou em quem o fornecedor do crédito está "acreditando" - irá honrar o compromisso assumido.

As formas de se "acreditar" no cliente podem ser divididas em qualitativas ou subjetivas, levando-se em conta a opinião de quem está avaliando o crédito e quantitativas ou objetivas / econométricas, uma vez que se utilizam modelos com forte apelo matemático. As formas qualitativas possuem a vantagem de tratar caso a caso; porém, possui a desvantagem da grande dependência da experiência do analista, do baixo volume de produção na análise e do envolvimento pessoal e até mesmo emocional da concedente.

Contrariamente, as formas quantitativas de concessão de crédito baseiam-se em modelos estatísticos ou econométricos, sobre as características dos clientes e sua relação com os produtos e/ou serviços, possuindo como grande desvantagem a impessoalidade e a rigidez de avaliação.

Ocorre, porém, que os métodos ora mencionados até o presente momento, não mensuram o risco de não recebimento após a ocorrência do atraso, nem mesmo dos valores a vencer; eles apenas mensuram o risco daqueles valores já vencidos, o que os tornam limitados, vez que, acabam se restringido a modelos de classificação dos clientes, sem calcular o valor do risco da carteira de contas a receber por parte da organização.

Scherr (1989) mostra que a concessão de crédito tem sido um dos principais componentes do crescimento do padrão de vida dos consumidores e do lucro das empresas, em função do crédito representar um fator de alavancagem da capacidade de gastos de indivíduos e empresas o que, em última instância, gera efeito multiplicador na produção e renda da economia.

Notadamente, o objetivo conceitual dos modelos mencionados é obter um conjunto de informações sobre o comprador, demonstrando sua real capacidade de honrar os compromissos assumidos num determinado período de tempo.

Souza e Chaia (1999) revelam que a política de crédito pós-concessão não se restringe à aprovação de limites e/ou à concessão aos consumidores, mas também, a monitoramento do desempenho, bem como os instrumentos ou técnicas usadas para a recuperação de valores em atraso. Os autores apresentam três fases que devem ser seguidas por parte da organização para 
o gerenciamento estratégico dos créditos de devedores duvidosos: (a) adoção de estratégias de monitoramento dos valores a receber, revertendo falhas no processo de análise de crédito; (b) definição das políticas de cobrança e recuperação de créditos vencidos. A eficiência dessas políticas pode ser mensurada observando-se a quantidade de consumidores inadimplentes ou insolventes da carteira da organização; (c) adoção de uma política de crédito adequada ao negócio da organização, englobando processos eficientes de avaliação e concessão de crédito, bons mecanismos de monitoramento das posições dos clientes inadimplentes para a recuperação rápida de valores inadimplentes. Ao agir desta forma, indicam os autores, as organizações poderão evitar problemas causados por projeções de fluxo de caixa que não se realizarão.

Por fim, Securato e Perobelli (2000) enfatizam que o risco de crédito já é e será cada vez mais o centro das atenções do mundo financeiro, ao ponto de os órgãos reguladores estarem sempre atentos e prontos a tomar medidas sobre esta questão. Além disso, é inegável que diversas crises ocorridas no Brasil com algumas instituições financeiras vêm levando esta preocupação, ao ponto de se desenvolverem técnicas sofisticadas de gestão do risco de crédito de forma a evitar prejuízos para aqueles que concederam crédito financeiro.

\subsection{ASPECTOS DA RESOLUÇÃO 2682/99 DO BANCO CENTRAL DO BRASIL}

Em 22 de Dezembro de 1999, o Conselho Monetário Nacional por intermédio do Banco Central do Brasil aprova a Resolução 2682 que surge para regular a análise de risco efetuada pelas instituições financeiras (VICENTE, 2001). Esta Resolução é baseada nos modelos internacionais de análise de riscos, principalmente nos modelos de rating definidos pelas agenciais internacionais, a exemplo das agências Standad \& Poors e Moody's duas das maiores agências na área, nos Estados Unidos (SILVA, 2006).

A Resolução 2682/99 define que as operações de crédito das instituições financeiras devem ser analisadas conforme dois critérios: (a) por ordem crescente de risco, onde "AA" representa risco zero e " $\mathrm{H}$ " o maior risco e (b) por dias vencidos.

Conforme Silva (2006), a Resolução 2682/99 não define o modelo padrão a ser seguido pelas instituições para a ordenação do risco, mas sim, ela dá diretrizes para se chegar ao cálculo do modelo a ser adotado, deixando a cargo das instituições a adoção do melhor critério de análise. Contudo, quanto ao critério de dias vencidos, a Resolução é bastante clara, 
fornecendo o percentual a ser empregado em cada uma das classificações dadas, conforme evidencia o Quadro 1.

Quadro 1: Critério de classificação Lei 2682/99

\begin{tabular}{|c|c|c|c|c|c|c|c|c|c|}
\hline Categoria & AA & A & B & C & D & E & F & G & H \\
\hline $\begin{array}{c}\text { Dias } \\
\text { Atraso }\end{array}$ & 0 & $0-14$ & $15-30$ & $31-60$ & $61-90$ & $91-120$ & $121-150$ & $151-180$ & $>180$ \\
\hline Percentual & $0 \%$ & $0,5 \%$ & $1 \%$ & $3 \%$ & $10 \%$ & $30 \%$ & $50 \%$ & $70 \%$ & $100 \%$ \\
\hline
\end{tabular}

Fonte: Adaptado de Silva (2003, p.71-72)

Segundo Marques (2002), o critério adotado pela Resolução 2682/99 é extremamente conservador e, por vezes, prejudicial às instituições, por que as obriga a reservar uma maior parcela de recursos na forma de provisões e reservas, que poderia estar sendo mais bem empregada em sua operação para geração de recursos.

Os critérios definidos pelo Banco Central na forma da Resolução 2682/99 para as instituições financeiras, serão aqui estendidos para uma IPEMF, para análise de sua carteira de clientes e definição do risco de inadimplência, estimado na forma de Provisão para Devedores Duvidosos (PDD). Para estimação do melhor modelo de insolvência é utilizado técnica de regressão logística.

A PDD, também chamada de Provisão para Créditos de Liquidação Duvidosas (PCLD), tem como uma de suas funções fazer com que o resultado contábil das empresas ou instituições espelhe as prováveis perdas decorrentes de insolvência em sua carteira de crédito, nas instituições financeiras ou contas a receber para as demais empresas. A PDD também pode ser considerada uma ferramenta administrativa que demonstra a qualidade da carteira de crédito das empresas, fornecendo bons indícios para avaliação das políticas de crédito em vigor.

\section{ASPECTOS METODOLÓGICOS}

Nesta seção é abordada a metodologia utilizada no presente trabalho, dividido em duas subseções que podem ser assim sumarizadas: a subseção 3.1 apresenta as características da amostra empregada para análise e 3.2 demonstra como a pesquisa empregada é caracterizada. 


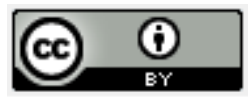

\subsection{A COLETA DOS DADOS}

Para a execução desta pesquisa foram utilizados inicialmente dados disponíveis na administração de uma mantenedora de vinte e uma IPEFMs, situada no Estado do Paraná.

Coletou-se da referida base de dados, informações referentes aos anos de 2004 a 2006, respectivamente: informações sobre 6.323 cadastros em um universo de 9.339 cadastros classificados junto às instituições atualizados até junho de 2006; informações sobre 5.711 cadastros em um universo de 8.533, atualizados até dezembro de 2004 e informações sobre 6.395, em um universo de 9.719 cadastros atualizados até dezembro de 2005.

A classificação de adimplência ou inadimplência baseia-se no fato de existir ou não algum saldo devedor em aberto, relativo ao cadastro do responsável financeiro pelo aluno. Não referenciando nomes ou documentos, o estudo visa estimar o valor da Provisão para Devedores Duvidosos a ser constituído com base nos critérios adotados pela Resolução $2682 / 99$.

As variáveis consideradas na análise são: (a) saldo devedor; (b) quantidade de parcelas em atraso; (c) idade; (d) cidade do responsável; (e) renda total; (f) existência de percentual de desconto; (g) valor da mensalidade na escola em questão; (h) valor da matrícula; (i) se possui membro da família naquela escola ou não, (j) Filho de funcionário, (k) Se continua registrado na escola ou não e (1) Sexo do Responsável.

\subsection{CARACTERIZAÇÃO DA PESQUISA}

Em relação à natureza da aplicação esse trabalho pode ser visto como uma pesquisa aplicada, já que busca solucionar um problema concreto. No que diz respeito aos objetivos da pesquisa, o trabalho pode ser caracterizado como uma pesquisa qualitativa descritiva dado que não foi utilizado nenhum teste de hipóteses, pois tal como relata Ribeiro e Cruz (2004) esse tipo de pesquisa tem por objetivo estudar, analisar, registrar e interpretar os fatos do mundo físico sem a interferência do pesquisador.

Essa pesquisa também pode ser caracterizada quanto à aquisição de referências bibliográficas. Neste caso, ela pode ser vista como uma pesquisa bibliográfica que tem por finalidade conhecer algumas contribuições científicas na área dos negócios internacionais. Oliveira (2000) ressalta que a pesquisa bibliográfica acaba se transformando em rotina para os pesquisadores e profissionais que necessitam de constante atualização. A pesquisa pode ainda 


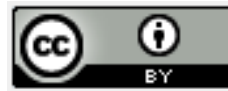

ser caracterizada em função do tempo de coleta. Nesse caso, o referido trabalho pode ser visto como um estudo de natureza longitudinal.

\section{APRESENTAÇÃO E ANÁLISE DOS RESULTADOS}

Para a base de dados obtida junto a mantenedora de vinte e uma IPEFMs, com data de corte de Dezembro de 2004, Dezembro de 2005 e Junho de 2006, respectivamente, foram efetuados os seguintes procedimentos operacionais: (a) selecionados todos os registros que possuíam valor de rendimentos superiores a $\mathrm{R} \$ 300,00$ e inferiores a $\mathrm{R} \$ 30.000,00$; (b) retirados da amostra todos os registros sem nome dos discentes, (c) identificados os responsáveis com mais de um filho registrado na IPEFM, para tanto, procurou-se substituir o nome do responsável por um valor numérico, de forma que números iguais correspondessem ao mesmo responsável e (d) foram desconsiderados da amostra todos os dados cuja idade do responsável financeiro fosse menor do que 18 anos e maior do que 100 anos. O resumo dos procedimentos efetuados encontra-se apresentado na Tabela 1.

Tabela 1: Resumo dos procedimentos efetuados nos dados 2004, 2005 e 2006

\begin{tabular}{lccc}
\hline \multicolumn{1}{c}{ Descrição } & Qnt Registros & Qnt Registros & Qnt Registros \\
& Dez/2004 & Dez/2005 & Jun/2006 \\
\hline Base dados & 8.533 & 9.719 & 9.339 \\
Itens desconsiderados: & & & 2.934 \\
$\bullet \quad$ Renda total $>\mathrm{R} \$ 30.000 \mathrm{e}<\mathrm{R} \$ 300$ & 2.781 & 3.261 & 82 \\
$\bullet \quad$ Idade Responsável $>100 \mathrm{e}<18$ anos & 41 & 63 & 6.323 \\
\hline Total válido para análise da PDD & 5.711 & 6.395 & \\
\hline
\end{tabular}

Verificou-se ainda que os dados coletados não possuem característica que levem à distribuição normal de probabilidade. Conforme descrito por Marques (2002), a desproporcionalidade entre os créditos que encontram-se adimplentes e os que encontram-se inadimplentes são, em geral, os responsáveis pela não normalidade dos dados analisado.

Visando a construção de um modelo para a estimação da provisão de perdas com os créditos concedidos, descrito na seção 4.1 do presente trabalho apresenta-se a aplicação da Resolução 2682/99 sobre as bases de dados de 2004, 2005 e 2006, respectivamente, levandose em conta a aplicação dos critérios de dias em atraso, na seção 4.2 é demonstrado o cálculo 
da perda potencial para os dados em análise em comparação com a provisão calculada com base na Resolução 2682/99 e na seção 4.3 é demonstrado o cálculo da probabilidade de perda potencial para o estabelecimento de ensino.

\subsection{APLICAÇÃO DA RESOLUÇÃO 2682/99 QUANTO AOS PERÍODOS DE ATRASO}

Nos dados da amostra resultante dos procedimentos descritos anteriormente, são aplicados os critérios indicados na referida norma, quanto aos dias de atraso, conforme demonstrado pela Figura 1, obtendo-se o resultado apresentado nas Tabelas 2, 3 e 4, respectivamente.

Tabela 2: Aplicação dos critérios de atraso conforme resolução 2.682/99 - 2006

\begin{tabular}{cccccc}
\hline Faixa_Dias & Cat_Bacen & \%_Prov & Quantidade & Saldo_em_aberto & Provisão_Bacen \\
\hline 0 & AA & $0 \%$ & 3.591 & $974.054,00$ & - \\
\hline $1-30$ & B & $1 \%$ & 1.280 & $170.422,42$ & $1.704,22$ \\
\hline $31-60$ & C & $3 \%$ & 515 & $138.356,36$ & $4.150,69$ \\
\hline $61-90$ & D & $10 \%$ & 315 & $140.755,03$ & $14.075,50$ \\
\hline $91-120$ & E & $30 \%$ & 159 & $108.616,20$ & $32.584,86$ \\
\hline $121-150$ & F & $50 \%$ & 109 & $100.049,74$ & $50.024,87$ \\
\hline $151-180$ & G & $70 \%$ & 104 & $104.008,36$ & $72.805,85$ \\
\hline$>181$ & H & $100 \%$ & 250 & $411.263,40$ & $411.263,40$ \\
\hline Total geral & & & 6.323 & $2.147 .525,51$ & $586.609,39$
\end{tabular}

Analisando-se a Tabela 2, é possível verificar que, para a amostra dos dados de 2006, aproximadamente 57\% da quantidade de registros (3.591) foram considerados adimplentes, não necessitando, portanto, estabelecer a provisão por dias de atraso. Verifica-se também, que nenhum registro foi classificado na faixa "A", devido à base de dados possuir responsáveis financeiros em atraso, na forma de número de parcelas e não em dias de atraso, com isso, ao efetuar a transformação dos dados, todas as parcelas com dias de atraso, situadas entre 1 e 30 foram consideradas na categoria "B" com provisão estipulada de $1 \%$.

Em relação aos valores calculados para a provisão, verifica-se que aproximadamente $70 \%$ do total, ou R $\$ 411.263,40$, concentram-se em $4 \%$ do total dos registros, ou 250, e estão inadimplentes a mais de 180 dias, sendo provisionados em 100\%. Com esta classificação é possível verificar que existe uma baixa quantidade de registros encontra-se inadimplente, mas, 
com um elevado valor de atraso impactando significativamente no valor da provisão calculada.

Tabela 3: Aplicação dos critérios de atraso conforme resolução 2.682/99 - 2005

\begin{tabular}{cccccc}
\hline Faixa_Dias & Cat_Bacen & \%_Prov & Quantidade & Saldo_em_aberto & Provisão_Bacen \\
\hline 0 & AA & $0 \%$ & 3.526 & $898.187,00$ & \\
\hline $1-30$ & B & $1 \%$ & 1.217 & $105.881,41$ & $1.058,81$ \\
\hline $31-60$ & C & $3 \%$ & 525 & $115.610,38$ & $3.468,31$ \\
\hline $61-90$ & D & $10 \%$ & 317 & $128.025,74$ & $12.802,57$ \\
\hline $91-120$ & E & $30 \%$ & 169 & $109.462,98$ & $32.838,89$ \\
\hline $121-150$ & F & $50 \%$ & 111 & $96.366,50$ & $48.183,25$ \\
\hline $151-180$ & G & $70 \%$ & 124 & $123.908,52$ & $86.735,96$ \\
\hline$>181$ & H & $100 \%$ & 469 & $819.803,20$ & $819.803,20$ \\
\hline Total geral & & & 6.458 & $2.397 .245,73$ & $1.004 .890,99$ \\
\hline
\end{tabular}

$\mathrm{Na}$ amostra de dados relativos ao ano de 2005, conforme evidenciado na Tabela 3, é possível verificar que aproximadamente $55 \%$ da quantidade de registros, correspondente a 3.526 registros, são adimplentes em 2005, contra 57\% demonstrado na Tabela 2 para a base de dados de 2006.

Em relação aos valores calculados para a provisão, verifica-se que aproximadamente $81 \%$ do total, ou R $\$ 819.803,20$, concentra-se em $7 \%$ dos registros, ou 469 e estão inadimplentes a mais de 180 dias, sendo provisionados em 100\%, em relação aos $70 \%$ apresentados na amostra de dados relativos ao ano de 2006. 
Analisando-se os dados para o ano de 2004, conforme evidenciados na Tabela 4, é possível verificar que aproximadamente $49 \%$ da quantidade de registros, correspondente a 2.780 registros, são adimplentes em 2004, contra 55\% em 2005, conforme a Tabela 3 e 57\% no ano de 2006, conforme a Tabela 2. Com isso, é possível verificar que há uma evolução na qualidade dos registros da mantenedora das IPEFMs, tendo em vista o aumento da base de dados ocorrida entre 2004 e 2006, respectivamente.

Tabela 4: Aplicação dos critérios de atraso conforme resolução 2.682/99 - 2004

\begin{tabular}{cccccc}
\hline Faixa_Dias & Cat_Bacen & \%_Prov & Quantidade & Saldo_em_aberto & Provisão_Bacen \\
\hline 0 & AA & $0 \%$ & 2.780 & $647.079,00$ & 0 \\
\hline $1-30$ & B & $1 \%$ & 1.243 & $84.005,99$ & 840,06 \\
\hline $31-60$ & C & $3 \%$ & 532 & $97.173,47$ & $2.915,20$ \\
\hline $61-90$ & D & $10 \%$ & 291 & $96.257,52$ & $9.625,75$ \\
\hline $91-120$ & E & $30 \%$ & 165 & $96.118,42$ & $28.835,53$ \\
\hline $121-150$ & F & $50 \%$ & 114 & $92.080,69$ & $46.040,35$ \\
\hline $151-180$ & G & $70 \%$ & 105 & $103.389,93$ & $72.372,95$ \\
\hline Total geral & H & $100 \%$ & 481 & $875.706,57$ & $875.706,57$ \\
\hline
\end{tabular}

Em relação aos valores calculados para a provisão, verifica-se que aproximadamente $84 \%$ do total, ou $\mathrm{R} \$ 875.706,57$, concentram-se em $8 \%$ do total de registros, ou 481, e estão inadimplentes a mais de 180 dias, sendo provisionados em $100 \%$, em relação aos $81 \%$ apresentados em 2005 e dos 70\% apresentados na amostra de dados de 2006. Neste caso, também é possível verificar a presença de uma evolução positiva, no sentido de redução do volume provisionado, quando comparados os anos de 2004, 2005 e 2006, respectivamente.

\subsection{CÁlCULO DA PERDA LÍQUIDA DOS CRÉDITOS ANUALMENTE}

Para aprimoramento do modelo de previsão de perdas construído com base na Resolução 2682/99, e como uma estratégia adotada para a otimização da gestão dos créditos em atraso, pode-se comparar a provisão para perdas calculada com base nos critérios da Resolução 2682/99 com a provisão para perdas calculada com base nos valores recuperados na carteira em análise.

Para tanto, há necessidade de calcular a Perda Líquida pautando-se em uma taxa histórica ou aproximada, dos valores recuperados. A taxa histórica obtida junto à 
administração da mantenedora das IPEFMs em análise demonstra que, em média, $10 \%$ do total de receitas obtidas pela Instituição, são consideradas como perdas. Com isso, para cada um dos anos em análise, é efetuado o cálculo da taxa efetiva de perda dos saldos, conforme demonstrado na Tabela 5.

Tabela 5: Cálculo da perda efetiva dos saldos não recuperados

\begin{tabular}{c|c|c|c}
\hline & 2004 & 2005 & 2006 \\
\hline Valor total: & $2.091 .811,59$ & $2.397 .245,73$ & $2.147 .525,51$ \\
$(\mathrm{x}) \%$ Perda total & $10 \%$ & $10 \%$ & $10 \%$ \\
\hline$(=)$ & $209.181,16$ & $239.724,57$ & $214.752,55$ \\
& & & \\
Perda efetiva: & $209.181,16$ & $239.724,57$ & $214.752,55$ \\
$(\div)$ Total de maus & $1.444 .732,59$ & $1.499 .058,73$ & $1.173 .471,51$ \\
\hline$(=) \%$ Perda s/ Maus & $14 \%$ & $16 \%$ & $18 \%$ \\
\hline Recuperados & $\mathbf{8 6 \%}$ & $\mathbf{8 4 \%}$ & $\mathbf{8 2 \%}$ \\
\hline
\end{tabular}

Avaliando-se os valores apresentados na Tabela 5, verifica-se que houve um sensível aumento no percentual dos saldos não recuperados entre 2004 e 2006. Esta evolução pode ser explicada, em parte, pela redução dos saldos em aberto, ou total da carteira, que é proporcionalmente menor do que a redução dos saldos em atraso, para o período em análise. Contudo, mesmo com a evolução apresentada, a perda líquida calculada para os dados de 2004 e 2006, conforme demonstrado na Tabela 6, mostra uma leve redução no montante da Perda Líquida.

Tabela 6: Cálculo do valor recuperado e da perda líquida

\begin{tabular}{c|c|c|c|c|c|c}
\hline \multicolumn{2}{c}{ Qnt } & Total R\$ & Recuperados & Perda Liq & $\begin{array}{c}\text { Média } \\
\text { Perda }\end{array}$ & $\begin{array}{c}\text { Prob. } \\
\text { Perda Liq }\end{array}$ \\
\hline 2004 & 5711 & $2.091 .811,59$ & $1.831 .759,72$ & $260.051,87$ & 45,54 & $12,43 \%$ \\
\hline 2005 & 6458 & $2.397 .245,73$ & $2.127 .415,16$ & $269.830,57$ & 41,78 & $11,26 \%$ \\
\hline 2006 & 6323 & $2.147 .525,51$ & $1.936 .300,64$ & $211.224,87$ & 33,41 & $9,84 \%$ \\
\hline
\end{tabular}

A Perda Líquida também pode ser considerada como o valor do Risco de Inadimplência Esperado, uma vez que ele representa o montante comprometido nas operações com probabilidade de não serem honrados. Para os anos de 2004 a 2006, respectivamente, o montante de Perda Líquida, ou seja, o valor total de saldos em aberto em atraso menos a 


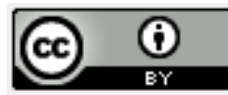

recuperação dos créditos, é de $\mathrm{R} \$ 260.051,87$ para o ano de 2004, $\mathrm{R} \$ 269.830,57$ para 2005 e $\mathrm{R} \$ 211.224,87$ para 2006.

A Perda Líquida, se considerada como base para o cálculo da provisão para perdas da mantenedora das IPEFMs, apresenta uma considerável diferença em relação a provisão sugerida pelo aplicação dos critérios de dias em atraso da Resolução 2682/99, conforme podese verificar através da comparação dos valores apresentada na Figura 1.

A partir da análise da Figura 1 é possível verificar que a aplicação dos critérios de dias de atraso constantes na Resolução 2682/99 apresentam resultados mais conservadores do que os resultados sugeridos pela aplicação do critério de Perda Líquida. Esta análise pode servir para comprovar a afirmação de Marques (2002) sobre a quantidade de recursos reservados para cobertura dos possíveis prejuízos com inadimplência, recursos estes que poderiam ser melhor empregados nas atividades da empresa, para geração de resultados.

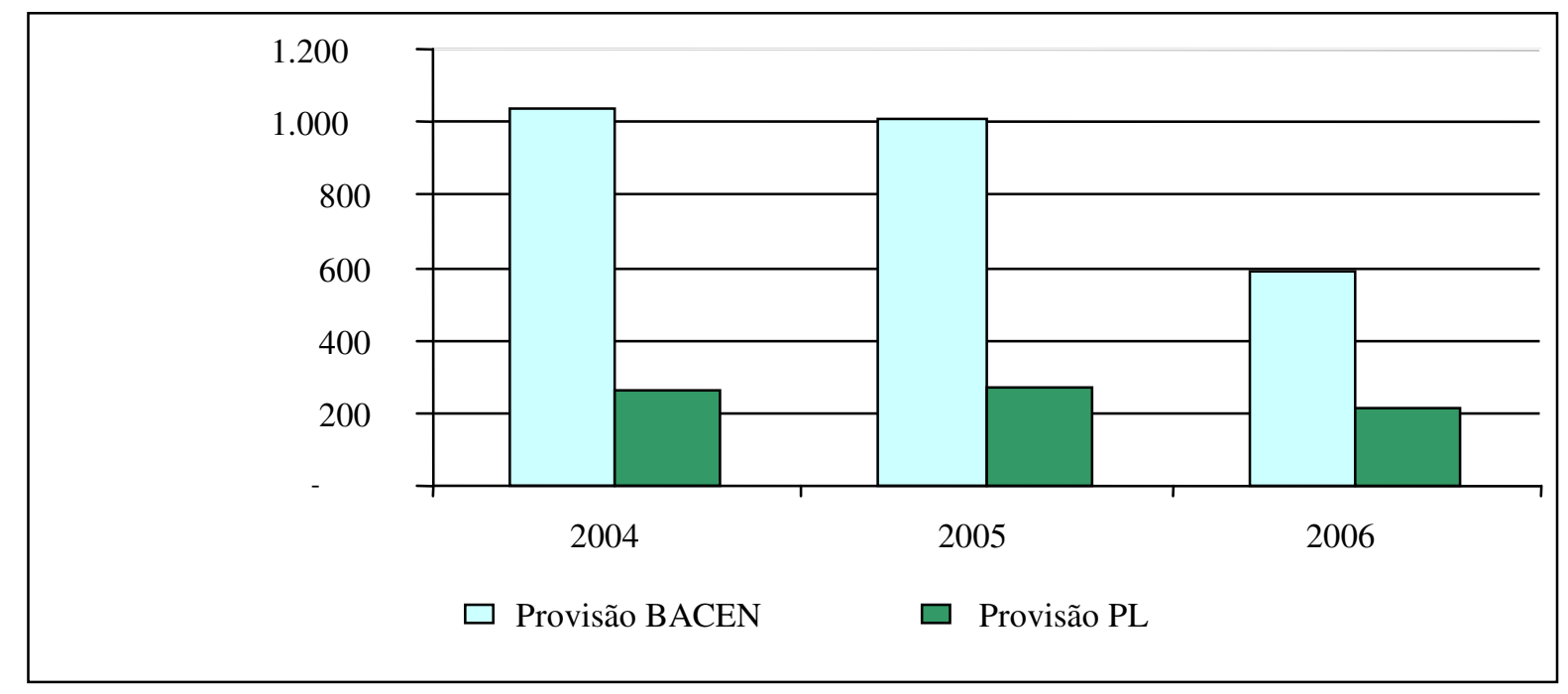

Figura 1: Comparação a partir da resolução 2682/99 versus Perda Liquida (PL)

A Probabilidade de Perda Líquida no modelo desenvolvido é mensurada em relação ao saldo em aberto das operações, com isso, é possível verificar que a Perda Líquida ou Risco de Inadimplência correspondendo a um valor igual a 9,84\% do total em aberto. $\mathrm{O}$ valor médio expresso em reais $(\mathrm{R} \$)$ da perda é calculado em relação ao número de casos considerados em cada faixa de atraso. O Desvio Padrão da Probabilidade de Perda é estimada com base no saldo médio das operações por faixa em relação a Probabilidade de Perda existente. 


\subsection{CÁLCULO DA PERDA POTENCIAL (PPP)}

Além de se efetuar o cálculo do valor a ser provisionado como possível perda, a partir dos critérios desenvolvidos pela Resolução 2682/99, é possível calcular a perda potencial ou perda não esperada (SECURATO, 2002), ou seja, o montante que a mantenedora das IPEFMs pode apurar como prejuízo não recuperável sobre o total dos saldos em aberto, devido a outros fatores não abrangidos pela amostra coletada e nem pelo modelo de risco aqui adotado.

Segundo Marques (2002), o cálculo da perda potencial está intrinsecamente relacionado com a volatilidade dos dados em análise. A perda potencial corresponde à variância em torno do Risco de Inadimplência estimado. Com isso, verifica-se que a perda potencial é um valor expressado com base no valor calculado para a perda líquida estimada. Este valor representa o risco de crédito a receber calculado para a amostra analisada.

A notação utilizada nesse trabalho pode ser expressa algebricamente tal como encontra-se em (1).

$$
P P \%=\sqrt{\left(\sum_{i=1}^{N} w_{i}^{2} \sigma_{1}^{2}+\sum_{i=1}^{N} \sum_{\substack{j=1 \\ 1 \neq j}}^{N} w_{i} w_{j} \sigma_{i} \sigma_{j} \rho_{i, j}\right)}
$$

onde $N$ corresponde ao número de observações, $w_{i}$ e $w_{j}$ indicam a proporção do saldo dos créditos a receber por faixa de rating, $\sigma$ é o desvio padrão da probabilidade de perda de cada variável e $\rho_{i, j}$ representa a correlação entre essas variáveis. A expressão denotada anteriormente apresenta duas equações a serem consideradas: uma para indicar o risco de inadimplência e a outra para indicar o risco diversificável quando se leva em consideração a relação entre os ativos. O resultado de tal expressão é um percentual que aplicado ao valor do risco de inadimplência, demonstra o valor expresso em reais (R\$) da perda potencial (PHELAN; ALEXANDER, 2000 apud MARQUES, 2002).

O valor da correlação entre os créditos a receber que constituem a base de dados, tende a ser muito baixa ou inexistente, uma vez que esta encontra-se associada a uma probabilidade de que dois ou mais créditos a receber venham se tornar inadimplentes dentro do mesmo horizonte de tempo. Para efeito desta pesquisa, vale salientar que é adotado o valor igual a $2 \%$ como o baixo grau de correlação entre os dados amostrados, estimado a partir do histórico desses dados. 
Na Tabela 7, encontra-se demonstrado o valor calculado da perda potencial para os anos de 2004 a 2006, respectivamente.Verifica-se com base na Tabela 7 que o índice apurado para o ano de 2004 equivale a 2,45\% do risco do crédito a receber ou da Perda Potencial. Por outro lado, estima-se para o ano de 2005 o valor igual a 2,01\% do risco de crédito a receber e de $1,71 \%$ do risco de crédito apurado para o ano de 2006. Com isso, é possível analisar que além da provisão proposta, $\mathrm{R} \$ 6.363,96$ para 2004, $\mathrm{R} \$ 5.423,87$ para 2005 e $\mathrm{R} \$ 2.474,83$ para 2006 pode ser efetivamente registrados como perdas por outros motivos não considerados pelo modelo. Cabe salientar ainda que a provisão proposta com base no modelo estimado, pode ser vista como uma forma de prevenção contra as perdas inesperadas.

Tabela 7: Probabilidade de Perda Potencial

\begin{tabular}{c|c|c}
\hline Anos & PPP (\%) & PPP (R\$) \\
\hline 2006 & $1,17 \%$ & $2.474,83$ \\
\hline 2005 & $2,01 \%$ & $5.423,87$ \\
\hline 2004 & $2,45 \%$ & $6.362,96$ \\
\hline
\end{tabular}

No período analisado há indícios de que existe uma tendência de queda da provisão para devedores duvidosos. Como decorrência do aumento da receita haverá uma reversão com o aumento dos investimentos em infra-estrutura. Estes resultados aplicam-se a esta instituição de ensino analisada.

\section{CONSIDERAÇÕES FINAIS E RECOMENDAÇÕES}

Tendo em vista que há parca literatura sobre a análise de crédito em instituições de ensino, o presente trabalho visou efetuar uma aplicação da Resolução 2682/99 do Banco Central, destinada originalmente às instituições financeiras, no sentido de identificar a inadimplência acumulada na mantenedora e em cada uma das vinte e uma IPEFMs em estudo, com o possível valor de perda a ser provisionado.

Para uma análise mais completa dos dados, sugere-se a aplicação da segunda parte da Resolução 2.682/99, no tocante a análise rating. Nas análises de rating se classificam as operações em relação as suas variáveis, em uma determinada escala ou ranking prédeterminado, a exemplo dos modelos de créditos. 
Conforme critérios apresentados no art. 2, da Resolução 2.682/99, mesmo que não seja mencionada a palavra rating, as análises devem considerar informações de fontes fidedignas internas e externas às empresas, possuírem critérios claros e bem definidos e, no mínimo, abrangerem as seguintes análises: (a) dos tomadores dos empréstimos e seus garantidores quanto a capacidade de honrar o pagamento da dívida contraída e (b) quanto a operação contraída. Ficando a cargo das instituições a melhor forma de aplicação da legislação.

Os valores da provisão para perdas obtidas com a aplicação dos critérios constantes na Resolução 2682/99 quanto a dias de atraso, foram comparados com a aplicação do critério de Perda Líquida para a mesma base. Os resultados demonstram que a Resolução 2682/99 apresentou resultados mais conservadores, com a sugestão de um alto grau de recursos reservados para cobertura dos riscos de créditos existentes.

Os resultados aqui apresentados mostraram que a Resolução 2682/99 quanto da aplicação do critério de dias de atraso para a constituição de Provisão para Perdas com Créditos de Liquidação Duvidosa, não foi totalmente compatível com as características dos créditos de uma mantenedora das IPEFMs, apresentado resultados muito conservadores devido ao alto volume de recursos reservados. Contudo, ela apresenta as diretrizes que quando combinadas com outras técnicas, como os critérios de Perdas Líquidas ou Perdas Potenciais, podem servir de guia para a tomada de decisões dentro da mantenedora e das vinte e uma IPEFMs, ajudando a prevenir possíveis perdas e a otimização dos recursos existentes.

\section{REFERÊNCIAS}

BANCO CENTRAL DO BRASIL - BACEN. Resolução 2.682/99. Dispõe sobre critérios de classificação das operações de crédito e regras para constituição de provisão para créditos de liquidação duvidosa. Brasilia: http://www.bcb.gov.br, 2000.

BERNSTEIN, P. L. Against the Gods: The Remarkable Story of Risk. New York: John Wiley \& Sons, 1998.

BESSIS, J. Risk Management in Banking. London: John Wiley \& Sons, 1998.

CHU, V.; SCHECHTMAN, R. O Uso de Informações no Crédito Bancário. Economia Bancária e Crédito - Avaliação de 4 anos do Projeto, VII: 68-77, Dez-2003.

COMISSÃO DE VALORES MOBILIÁRIOS-CVM. Provisão para Créditos de Liquidação Duvidosa. OFÍCIO-CIRCULAR/CVM/SNC/SEP/N ${ }^{\circ}$ 01/00 de 31 de janeiro de 2000. http://www.cvm.gov.br, 2000. 


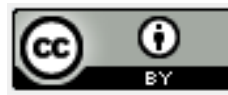

EMERY, D. R. e FINNERTY, J. D. Corporate Financial Management. New Jersey: Prentice-Hall, 1997.

GITMAN, L. J. Princípios de Administração Financeira. 7 ed., São Paulo: Harbra, 1997.

HAIR Jr., J. F. Fundamentos de Métodos de Pesquisa em Administração. Porto Alegre: Bookman, 2005.

INSTITUTO BRASILEIRO DE CONTADORES. Comunicado IBRACON nº 04/00 de 13 de Dezembro de 1999. http://www.ibracon.com.br, 2000.

LAKATOS, E. M.; MARCONI, M. A. Fundamentos da metodologia científica. 3a. ed. São Paulo: Atlas, 1991, 190p.

MARQUES, L. F. B. Gerenciamento do Risco de Crédito - Cálculo do Risco de Crédito para a Carteira de um Banco do Varejo. Dissertação de Mestrado, UFRG. Porto Alegre: fevereiro de 2002.

MARSHALL, C. Medindo e Gerenciando Riscos Operacionais em Instituições Financeiras. Rio de Janeiro: qualitymark ed., 2002.

OLIVEIRA, S. L. Tratado de metodologia científica: projetos de pesquisas, TGI, TCC, Monografias, Dissertações e Teses, 2 ed., São Paulo: Pioneira, 2000.

PRADO, BLASTOS e DUARTE Jr. Gerenciamento de Riscos de crédito em bancos de Varejo no Brasil. www.risktech.com.br. Portal brasileiro de tecnologia em risco, 2000.

RIBEIRO, U. e CRUZ, C. Metodologia Científica: teoria e prática. 2 ed., São Paulo: Axcel Books, 2004.

ROSS, S. A. et al. Corporate Finance. São Paulo: Atlas, 1995.

SALOMON, D. V. Como fazer uma monografia. 2a. ed. São Paulo: Martins Fontes, 1991, $240 \mathrm{p}$.

SANVICENTE, A. Z.; MINARDI, A. M. A. F. Identificação de Indicadores Contábeis Significativos para a Previsão de Concordatas de Empresas. Ibmec, Relatório de Pesquisa, outubro de 1999.

SECURATO, J. R. Crédito: Análise e Avaliação do risco. São Paulo: Saint Paul, 2002.

SECURATO, J. R. e PEROBELLI, F. F. C. Comparação entre Métodos de para Determinação do Valor Presente de uma Carteira de Crédito e de seu Risco. Cadernos de Pesquisas em Administração. São Paulo, v. 7, n. 4, out/dez, 2000.

SCHERR, F. C. Modern Working Capital Management. New Jersey: Prentice-Hall, 1989.

SILVA, J. P. Gestão e Análise de Risco de Crédito. São Paulo: Atlas, 2006. 
SOUZA, A. F.; CHAIA, A. J. Política de Crédito: Uma Análise Qualitativa dos Processos em TOSTA DE SÁ, G. Administração de Investimentos: Teoria de Carteiras e Gerenciamento do Risco. Rio de Janeiro: Qualitymark ed., 1999, 376p.

TOSTA DE SÁ, G. Administração de investimentos: teoria de carteiras e gerenciamento de risco. Rio de Janeiro: Qualitymark, 1999.

VAUGHAN, E. J. Risk management. New Baskerville: John Wiley \& Sons, 1997.

VICENTE, E. F. R. A Estimativa do Risco na Constituição da PDD. Dissertação de Mestrado, USP. São Paulo: maio de 2001.

ZAMORA, A. J. Bank Contingency Financing. New York: John Wiley \& Sons, 1990. 